Dossier: Religión y política en el mundo antiguo y contemporáneo

\title{
Apuntes sobre la secularización (y la desecularización) del Estado costarricense entre 1884 y $2016^{1}$
}

Jerry Espinoza Rivera Universidad de Costa Rica, Costa Rica jerryespinoza@yahoo.com

Recibido: 25 de setiembre de 2017

Aceptado: 20 de noviembre de 2017

\section{RESUMEN:}

La Constitución Política de Costa Rica establece que la religión católica es la religión del Estado (artículo 75), lo cual convierte a este país en el único Estado confesional en Latinoamérica. Sin embargo, un siglo atrás la relación entre la Iglesia y el Estado costarricense era muy diferente. A finales del siglo XIX, Costa Rica fue uno de los primeros países latinoamericanos que legalizó el divorcio y eliminó la educación religiosa de las escuelas públicas. Con el fin de explicar este viraje, este artículo distingue tres períodos en el proceso de secularización del Estado costarricense de 1884 a 2016. El primer período abarca desde la reforma educativa y las leyes anticlericales de 1884-86. El segundo período inicia con la alianza entre el gobierno y la jerarquía católica a inicios de la década de los años 40. Finalmente, el tercer período inicia en 2009, cuando una agrupación presentó un proyecto de ley que pretendía eliminar la confesionalidad del Estado costarricense. A partir del concepto de desecularización propuesto por Peter Berger, el artículo evidencia que el proceso de secularización en Costa Rica nunca ha sido lineal ni progresivo. Por el contrario, éste muestra que ha sido un proceso complicado, con avances y retrocesos.

Palabras clave: Iglesia y Estado en Costa Rica, secularización, desecularización.

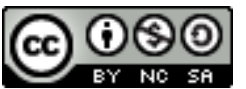

La Revista Estudios es editada por la Universidad de Costa Rica y se distribuye bajo una Licencia Creative Commons Atribución-NoComercial-Compartirlgual 3.0 Costa Rica. Para más información envíe un mensaje a revistaestudios.eeg@ucr.ac.cr. 


\begin{abstract}
The Political Constitution of Costa Rica establishes that Catholicism is the religion of the state (article 75), turning this country into the only remaining confessional state in Latin America. However, a century ago the relationship between the Church and the Costa Rican State was very different: At the end of the $19^{\text {th }}$ Century, Costa Rica became into one of the first Latin American countries that legalized the divorce and excluded religion from public schools. In order to explain this turn, the article distinguishes three periods in the secularization of the Costa Rican State from 1884 to 2016. The first period begins with the Reform and the anticlerical laws imposed by Liberal governments after 1884. The second period begins with the alliance between the Costa Rican government and the Catholic hierarchy after 1940. Finally, the third period begins in 2009, when a group submitted a bill to eliminate the Confessionality of the Costa Rican state. Following Peter Berger's conception of desecularization, the article reveals how the secularization process of the Costa Rican state has never been a linear or progressive process. By the contrary, it shows how the Costa Rican process of secularization has been complicated, with advances and retreats.
\end{abstract}

Key words: Church and State in Costa Rica, secularization, desecularization.

Costa Rica: Advances and Retreats in the Process of Secularization between 1884 and 2016

Introducción

A mediados de la segunda década del siglo XXI Costa Rica aún tenía el dudoso honor de ser el único Estado confesional en Latinoamérica. El artículo 75 de la Constitución Política vigente de 1949 establece al respecto que "La Religión Católica, Apostólica, Romana, es la del Estado, el cual contribuye a su mantenimiento, sin impedir el libre ejercicio en la República de otros cultos que no se opongan a la moral universal ni a las buenas costumbres" (Sistema Costarricense de Información Jurídica, s.f.).

\footnotetext{
(c) (i) (ㅇ)

La Revista Estudios es editada por la Universidad de Costa Rica y se distribuye bajo una Licencia Creative Commons Atribución-NoComercial-Compartirlgual 3.0 Costa Rica. Para más información envíe un mensaje a revistaestudios.eeg@ucr.ac.cr.
} 
Esta condición privilegiada que le concede la constitución a la Iglesia ha significado, entre otras cosas, que el Estado financie la educación religiosa de carácter obligatorio en escuelas públicas, así como a instituciones y organizaciones religiosas. Peor aún, ha justificado la injerencia de la Iglesia en la formulación de políticas públicas.

Sin embargo, un siglo atrás la relación entre la Iglesia y el Estado costarricense era completamente diferente. A finales del siglo XIX Costa Rica fue uno de los primeros países de la región en el que se legalizó el divorcio y se eliminó la educación religiosa de las escuelas públicas.

¿Cómo se explica este cambio? Este artículo pretende plantear ideas que den alguna luz al respecto. Con este fin, en primer lugar se examinará la discusión a favor y en contra de la tesis de la secularización. Más adelante, se distinguirán tres períodos en el proceso de secularización del Estado costarricense de 1884 a 2016. El primer período abarca desde la llegada al poder de los liberales y la implementación de la reforma educativa y las leyes anticlericales de 1884-86 hasta la llegada al poder de Rafael Ángel Calderón Guardia. El segundo período inicia con la alianza entre el gobierno y la jerarquía católica a inicios de la década de los años 40 y el tercer período inicia en 2009, cuando una agrupación denominada Movimiento por un Estado Laico en Costa Rica presentó un proyecto de ley que pretendía eliminar la confesionalidad del Estado costarricense. Las significativas

\section{(2) $\oplus \Theta(0)$}

La Revista Estudios es editada por la Universidad de Costa Rica y se distribuye bajo una Licencia Creative Commons Atribución-NoComercial-CompartirIgual 3.0 Costa Rica. Para más información envíe un mensaje a revistaestudios.eeg@ucr.ac.cr. 
diferencias entre estos períodos dan cuenta de la complejidad de este fenómeno en el caso costarricense, como se verá a continuación.

Secularización y desecularización

Desde Comte hasta Freud numerosos pensadores y estudiosos del fenómeno religioso han vaticinado un continuo declive de la religión en las sociedades occidentales e incluso su completa extinción. Según esta interpretación, el avance del progreso científico y de la educación laica, la pérdida de prestigio de las grandes religiones institucionalizadas, sumado a lo que Max Weber denominaba el "desencantamiento del mundo", ocasionarían que las personas en Occidente y el resto del mundo progresivamente abandonarían las creencias religiosas y que éstas perderan cada vez más importancia en la vida de las personas. Grosso modo, con algunas variantes significativas, esta interpretación pasó a denominarse la tesis de la secularización.

Durante las últimas décadas ha emergido una fuerte controversia entre sociólogos y estudiosos de la religión sobre la vigencia actual de esta teoría. Mientras algunos siguen reivindicando la tesis de la secularización y subrayan que en muchos países de Europa los indicadores de religiosidad no solo se ha estancado sino que muestran una progresiva disminución (cf. Pollack, 2008), otros autores consideran que la tesis de la secularización ya está superada. Estos últimos, por el contrario, hablan de un resurgimiento de las creencias religiosas en Occidente y en el resto del mundo, como lo evidencia el crecimiento de la 
religiosidad en países como Rusia o Polonia, el avance del Islam en muchos países o el incremento de grupos cristianos evangélicos integristas en muchos países de Latinoamérica.

Irónicamente, uno de los más acérrimos defensores de la tesis de la secularización, el sociólogo Peter Berger, se convirtió a finales de la década de los años 90 en uno de sus más fuertes críticos. Berger propuso que la tesis de la secularización debía ser revisada debido a que en algunos países se estaba dando un resurgimiento de la religión y una creciente injerencia de las religiones en la política. A este fenómeno Berger lo denomina desecularización (Karpov, 2010).

La desecularización no hace referencia al incremento de creyentes religiosos sino a la reapropiación religiosa de espacios que previamente habían sido secularizados (Karpov, 2010). Al proponer el concepto de desecularización, Berger critica el reduccionismo de las versiones más simplistas de la tesis de la secularización y subraya la complejidad y la diversidad de la secularización en diferentes contextos, especialmente fuera del mundo occidental. Contrario a lo que Comte, y junto con él la mayoría de los estudiosos de la religión de los siglos XIX y XX creían, Berger advierte que la secularización no es un fenómeno lineal ni unidimensional.

Existen numerosos ejemplos que muestran la complejidad y el carácter nolineal del fenómeno de la secularización. Uno de ellos es precisamente el caso de

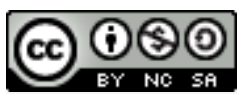

La Revista Estudios es editada por la Universidad de Costa Rica y se distribuye bajo una Licencia Creative Commons Atribución-NoComercial-Compartirlgual 3.0 Costa Rica. Para más información envíe un mensaje a revistaestudios.eeg@ucr.ac.cr. 
Costa Rica. La historia de las relaciones entre la Iglesia y el Estado costarricense evidencia que la secularización nunca ha sido un proceso continuo sino que ha tenido avances y retrocesos en diferentes periodos ${ }^{2}$.

Los orígenes del Estado confesional costarricense

La declaración de confesionalidad del Estado costarricense aparece en trece de las catorce constituciones que han existido en este país desde su independencia del Reino de España en 1821 Sin embargo, los orígenes de esta condición se remontan varios siglos atrás, al período de la Colonia española.

A mediados del siglo XVI España era un reino absolutista, reaccionario e intolerante que se había unificado tras la reconquista de la península ibérica y la caída de Granada en 1492. Además, la Inquisición española era una de las más implacables en Europa y tras la reconquista se dedicó a perseguir no solo a aquellos que eran considerados "herejes" sino también a los judíos y a los musulmanes, incluso aquellos que se habían convertido al cristianismo.

Ese régimen político clerical y retrógrado fue el que se implantó en las nuevas Colonias establecidas en América. Por esta razón, no es de extrañar que en la entonces provincia de Costa Rica, así como en las demás colonias españolas americanas no existiera una frontera claramente definida entre la esfera pública y la esfera religiosa. Tanto es así que, como señala Ana Lucía Fonseca (2008), durante la Colonia se confundían las leyes con las normas religiosas ya que no existía una clara separación entre lo que se consideraba delito y lo que la

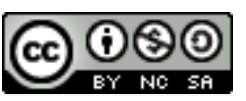

La Revista Estudios es editada por la Universidad de Costa Rica y se distribuye bajo una Licencia Creative Commons Atribución-NoComercial-CompartirIgual 3.0 Costa Rica. Para más información envíe un mensaje a revistaestudios.eeg@ucr.ac.cr. 
Iglesia consideraba pecado. Por eso era usual que los sacerdotes decidieran cuestiones legales y que los jueces dictaran sentencias por transgresiones religiosas.

No es casual por eso que la monarquía española se aliara con la Iglesia para imponer un rígido control del pensamiento. La corona le concedió a la Iglesia la autoridad legal para decidir cuáles contendidos podían impartirse y cuáles no. Por esta razón, las autoridades eclesiales implementaron una fuerte regulación de los contenidos de las materias que se impartían en escuelas y universidades. Eso significa que, entre otras cosas, los sacerdotes tenían la potestad de prohibir y censurar aquellos libros que consideraran amenazantes (Vargas, 1991). Este estricto control que ejercía la Iglesia sobre la educación significó que las ideas de la llustración fueran prácticamente desconocidas en Costa Rica hasta bien entrado el siglo XIX.

Esta condición solo empezó a cambiar a inicios del siglo XIX. Tras la guerra contra Francia y la expulsión de las tropas napoleónicas hubo un despertar del interés por la política en España. En ese contexto, muchos políticos e intelectuales españoles empezaron a simpatizar con las ideas republicanas y liberales de la Revolución Francesa y la Revolución Norteamericana. En 1810 algunos de ellos se reunieron en la ciudad de Cádiz con el fin de redactor una constitución que estableciera límites al poder casi ilimitado que hasta entonces tenía el monarca. Dos años más tarde las Cortes de Cádiz aprobaron la primera constitución de la 
historia española, la cual establecía, entre otras cosas, la separación de poderes y la abolición de la Inquisición. La Constitución de Cádiz de 1812 es el primer intento de crear un régimen monárquico parlamentario y liberal en España.

Sin embargo, en relación con el estatuto de la religión la Constitución de Cádiz es muy poco liberal y más bien reafirma el clericalismo medieval. A este respecto declara: "La religión de la Nación española es y será perpetuamente la católica, apostólica, romana, única verdadera. La Nación la protege por leyes sabias y justas, y prohíbe el ejercicio de cualquiera otra" (Fonseca, 2008, p. 129).

Esto es significativo porque, como señala Fonseca (2008), la Constitución de Cádiz es el modelo a partir del cual se redactarán las primeras constituciones costarricenses.

Tras la independencia de Costa Rica en 1821 hubo pocos cambios en la relación entre la Iglesia y el Estado. Según el historiador Claudio Vargas (1991), esto se explicaría por el escaso apoyo que en ese momento tenían las ideas liberales y por la extensa representación que tenía el clero entre los primeros representantes políticos durante los primeros años de vida independiente. Así por ejemplo, en la primera Junta de Notables que se formó en octubre de 1821, de un total de 29 miembros había nueve sacerdotes, es decir, casi una tercera parte de los electores (Vargas, 1991, p. 41).

Además, durante los primeros años de vida independiente las ceremonias religiosas estaban presentes hasta en las actividades más cotidianas. Blanco

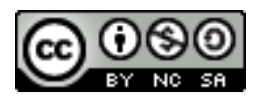

La Revista Estudios es editada por la Universidad de Costa Rica y se distribuye bajo una Licencia Creative Commons Atribución-NoComercial-CompartirIgual 3.0 Costa Rica. Para más información envíe un mensaje a revistaestudios.eeg@ucr.ac.cr. 
(1984) se refiere a la importancia que en ese entonces tenía el ceremonial religioso en las reuniones políticas:

Lo religioso era motivo de constante invocación en todos los actos; para la instalación del cabildo, sermón y misa del cura; después de la instalación, Te Deum cantado por el cura; renovación del cabildo, con el consejo del cura. Al principio de un libro de actas la invocación ritual: En el nombre del Padre, del Hijo y del Espíritu Santo (19).

Esta alianza entre la Iglesia y el Estado costarricense solo se empezó a cuestionar a mediados del siglo XIX, cuando empezaron a divulgarse las ideas del racionalismo y el positivismo procedentes de Europa, especialmente entre los grupos de intelectuales (Vargas, 1991).

\section{La periodización histórica y sus límites}

La periodización histórica ha sido un asunto controversial por razones harto evidentes. ¿Quién y cómo decide cuándo se termina un período y cuándo se inicia otro? Escoger un acontecimiento específico para separar un periodo de otro siempre es inevitablemente una decisión subjetiva y arbitraria. Sin embargo, desde una perspectiva metodológica la periodización histórica puede contribuir a comprender un fenómeno histórico.

En este caso específico, se propone distinguir tres períodos en la secularización del Estado costarricense tomando en cuenta acontecimientos

\section{(C) $(\Theta \odot \odot$}

La Revista Estudios es editada por la Universidad de Costa Rica y se distribuye bajo una Licencia Creative Commons Atribución-NoComercial-CompartirIgual 3.0 Costa Rica. Para más información envíe un mensaje a revistaestudios.eeg@ucr.ac.cr. 
históricos significativos en la relación entre la Iglesia y el Estado, de 1884 a 1940, de 1940 a 2009 y de 2009 a 2016.

Primer período de secularización (1884-1940): La Reforma

Uno de los primeros conflictos entre la Iglesia y el Estado costarricense estalló en 1835, cuando el entonces Jefe de Estado Braulio Carrillo decretó la abolición del diezmo (un impuesto de 10\% de las ganancias que se destinaba a la Iglesia). Sin embargo, este conflicto, básicamente económico, se resolvió en 1852, cuando el gobierno de Juan Rafael Mora firmó un concordato con la Santa Sede que reafirmó los privilegios económicos y políticos que había conservado la Iglesia tras la independencia, legalizó la injerencia de la Iglesia en las escuelas e incluso le otorgó la potestad de censurar libros (Picado, 1993).

Sin embargo, el acontecimiento que realmente inicia la secularización del Estado costarricense es la Reforma Liberal que se da a finales del siglo XIX. El conflicto entre la Iglesia y el Estado costarricense estalló en 1884, cuando el gobierno del entonces presidente Próspero Fernández decretó la expulsión del obispo Bernardo Augusto Thiel y proscribió las órdenes y las congregaciones religiosas. Tras la muerte repentina de Fernández a inicios de 1885 las medidas anticlericales fueron continuadas por su sucesor Bernardo Soto. A diferencia del conflicto anterior, este conflicto no se debió exclusivamente a motivaciones económicas sino sobre todo a profundas diferencias políticas (Vargas, 1991).

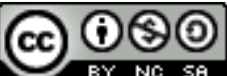

La Revista Estudios es editada por la Universidad de Costa Rica y se distribuye bajo una Licencia Creative Commons Atribución-NoComercial-CompartirIgual 3.0 Costa Rica. Para más información envíe un mensaje a revistaestudios.eeg@ucr.ac.cr. 
La Reforma Liberal de 1884-86 significó un avance significativo hacia la secularización del Estado costarricense. Durante los gobiernos de Fernández y Soto se adoptaron medidas tendientes a garantizar que se separara la religión del Estado. Según el antes citado Vargas (1991), algunas de las principales medidas tomadas fueron:

-La Reforma Educativa de 1886 impulsada por su Ministro de Educación Mauro Fernández, una reforma que incluyó la eliminación de las clases de religión de las escuelas públicas, el cierre de la Universidad de Santo Tomás y la apertura de colegios laicos en las ciudades principales: San José, Alajuela, Heredia y Cartago. -La legalización del matrimonio civil y el divorcio.

-La expropiación de los cementerios.

-La abolición del concordato de 1852.

-La secularización de los registros de nacimientos y defunciones (creación del Registro Civil).

Curiosamente, a pesar de estas medidas, la secularización del Estado costarricense no se expresó en un cambio en la condición legal de la Iglesia porque la confesionalidad estatal establecida en la Constitución de 1871 nunca fue puesta en cuestión. Por esta razón, se puede decir que la reforma liberal solo fue parcialmente exitosa.

El historiador Iván Molina (2007) propone que una de las principales razones que explican este fracaso es el hecho de que la reforma no contribuyera a

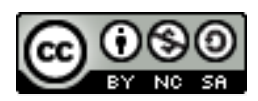

La Revista Estudios es editada por la Universidad de Costa Rica y se distribuye bajo una Licencia Creative Commons Atribución-NoComercial-Compartirlgual 3.0 Costa Rica. Para más información envíe un mensaje a revistaestudios.eeg@ucr.ac.cr. 
mejorar significativamente las condiciones de vida de las grandes mayorías. Según Molina (2007), la Reforma Liberal -a diferencia de la reforma social de los años 40 - solo benefició a una pequeña minoría privilegiada: la población urbana de clase media que tenía acceso a la educación y a la "alta cultura". Los campesinos, que en esa época constituían la vasta mayoría de la población, nunca se sintieron identificados con la reforma y por esta razón nunca lucharon para preservarla.

Esto explicaría por qué cuando Calderón Guardia llegó al poder en 1940 y decidió reestablecer la enseñanza religiosa obligatoria en las escuelas y colegios públicos de todo el país prácticamente se impuso sin que hubiera resistencia ni oposición organizada en contra de esta decisión (Molina, 2007).

En síntesis, este primer período puede caracterizarse como un período de avance significativo hacia la secularización del Estado costarricense en todos los ámbitos. La Reforma Liberal de 1884-86 significó un cambio en la tendencia que existía desde la Colonia de injerencia de la Iglesia en los asuntos públicos e inició un incipiente proceso de secularización inédito hasta ese momento. Durante las siguientes cinco décadas la injerencia del clero en la educación fue indudablemente menor que la que se había dado hasta ese momento.

Sin embargo, este avance solo fue parcial e incompleto porque la confesionalidad del Estado establecida en la Constitución de 1871 nunca estuvo en discusión y porque la Reforma Liberal nunca tuvo un fuerte arraigo popular.

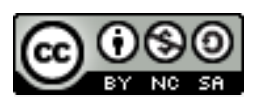

La Revista Estudios es editada por la Universidad de Costa Rica y se distribuye bajo una Licencia Creative Commons Atribución-NoComercial-CompartirIgual 3.0 Costa Rica. Para más información envíe un mensaje a revistaestudios.eeg@ucr.ac.cr. 
En 1940 la hegemonía casi incuestionable que habían mantenido los liberales durante más de setenta años llegó a su fin. Una nueva generación de políticos había crecido y en ese año llegó al poder. Una generación que estaba más interesada en valores como la justicia social y la solidaridad que en la defensa de un Estado separado de la religión. Su figura más destacada era el Doctor Rafael Ángel Calderón Guardia.

Calderón nació en una familia tradicional. Su padre era un conocido defensor del catolicismo conservador (Díaz-Arias, 2010). Estudió Medicina en la Universidad de Lovaina. Durante este período entró en contacto con las ideas de la Doctrina Social de la Iglesia propuesta por el papa León XIII en la encíclica Rerum Novarum: En esta encíclica, León XIII reivindica la defensa de los trabajadores a un trabajo y un salario digno y condena el capitalismo salvaje.

En contraste con la política que habían implementado los gobiernos liberales en materia de educación, una de las primeras decisiones tomadas por Calderón al llegar al poder fue decretar la reinstauración de la enseñanza religiosa de carácter obligatorio en las escuelas públicas (Díaz-Arias, 2010; Molina, 2007).

No obstante, inspirados en las ideas de la Doctrina Social de la Iglesia, el objetivo principal de Calderón y sus seguidores no era una reforma educativa sino una reforma laboral que mejorara las condiciones de vida de los trabajadores. Con este fin, Calderón se aproximó a la jerarquía de la Iglesia y más adelante al

\section{(c) (i) (2) (2)}

La Revista Estudios es editada por la Universidad de Costa Rica y se distribuye bajo una Licencia Creative Commons Atribución-NoComercial-Compartirlgual 3.0 Costa Rica. Para más información envíe un mensaje a revistaestudios.eeg@ucr.ac.cr. 
Partido Comunista. En 1943, firmó un pacto con el arzobispo de San José, Víctor Manuel Sanabria, y con el entonces líder del Partido Comunista, Manuel Mora.

Esta insólita alianza entre el gobierno, la Iglesia y el Partido Comunista hizo posible que se aprobara un Código de Trabajo muy avanzado para su época que otorgó significativos beneficios a los trabajadores, tales como la jornada de ocho horas, el derecho a cesantía y el derecho a huelga, así como la creación de la Caja Costarricense del Seguro Social, una institución creada con el fin de que el Estado brindara atención médica gratuita a todos los trabajadores. Estas medidas, ampliamente populares, permitieron que el calderonismo se convirtiera en una de las principales fuerzas políticas durante los siguientes sesenta años.

La presidencia de Calderón inició un período de avances sociales que mejoraron las condiciones laborales de los trabajadores. Sin embargo, al mismo tiempo este período inició una Contrarreforma educativa que echó abajo muchos de los avances alcanzados tras la reforma educativa liberal, especialmente tras la reinstauración de la educación religiosa obligatoria en las escuelas públicas (DíazArias, 2010).

Para Molina (2007), la reintroducción de clases de religión en las escuelas públicas significó además que se desencadenara una progresiva "recatolización" de la educación pública. Más aún, la Contrarreforma no solo afectó a las políticas educativas sino también a las políticas de salud pública: En el 2000, la Sala Constitucional decretó la prohibición de la fertilización in vitro alegando que los

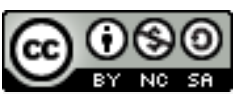

La Revista Estudios es editada por la Universidad de Costa Rica y se distribuye bajo una Licencia Creative Commons Atribución-NoComercial-Compartirlgual 3.0 Costa Rica. Para más información envíe un mensaje a revistaestudios.eeg@ucr.ac.cr. 
embriones debían ser considerados como sujetos humanos con los mismos derechos que los nacidos (Fuentes, 2014).

En resumen, este segundo período puede caracterizarse como un período de significativos avances en materia de legislación laboral, pero al mismo tiempo como un período de retroceso en materia de secularización del Estado costarricense, especialmente en materia de educación y salud públicas.

Tercer período de secularización (2009-2016): Avances y retrocesos

En setiembre de 2009, una agrupación denominada Movimiento por un Estado Laico en Costa Rica (MELCR), con el respaldo de un grupo de diputados de varios partidos, presentó ante la Asamblea Legislativa un proyecto de ley que pretendía convertir a Costa Rica en un Estado laico. EI MELCR se creó a finales de 2008 a partir de la alianza de un conjunto de organizaciones, entre ellas la Escuela Ecuménica de Ciencias de la Religión de la Universidad Nacional, la Universidad Bíblica Latinoamericana, la Iglesia Luterana de Costa Rica, el Centro de Investigación y Promoción para América Central de Derechos Humanos (CIPAC), el Movimiento Diversidad, la Agenda Política de Mujeres, la Colectiva por el Derecho a Decidir y la Asociación Costarricense de Humanistas Seculares (Arguedas, 2011).

El proyecto de ley del MELCR pretendía una modificación de los artículos 75 y 194 de la constitución. En el caso del artículo 75 se pretendía eliminarlo y sustituirlo por otro que dijera:

\section{(c) (1) 8 (2)}

La Revista Estudios es editada por la Universidad de Costa Rica y se distribuye bajo una Licencia Creative Commons Atribución-NoComercial-CompartirIgual 3.0 Costa Rica. Para más información envíe un mensaje a revistaestudios.eeg@ucr.ac.cr. 
Toda persona es libre de adoptar y profesar una religión que sea respetuosa de los derechos humanos, o bien de no adoptar ninguna.

El Estado será neutral en materia religiosa, pero garantizará el ejercicio de esta libertad, conforme a la ley (Asamblea Legislativa de la República de Costa Rica, 2009).

A pesar de que el proyecto de ley fue retirado unos días después debido al retiro de la firma que hicieron varios de los diputados que originalmente lo habían apoyado, en parte influidos por la fuerte campaña en contra que se desencadenó tras su presentación (Arguedas, 2011), su sola presentación posibilitó que por primera vez en más de medio siglo se sometiera a discusión la condición legal privilegiada de la Iglesia y la estrecha relación que históricamente ha existido entre esta institución y el Estado costarricense.

Al mismo tiempo, durante este período se dan otros significativos avances hacia la secularización del Estado. Uno de los más importantes fue la resolución de la Sala Constitucional en febrero de 2010 que declara la inconstitucionalidad de la Missio Canónica, una autorización que era exigida por la Iglesia a los profesores de educación religiosa para impartir lecciones en las escuelas, públicas o privadas. En su resolución, la Sala declara que la única institución que podía autorizar o rechazar a los aspirantes a docentes era el Ministerio de Educación Pública y, tal vez lo más significativo, que la confesionalidad del Estado establecida en el artículo 75 no implicaba que el Estado renunciara a su potestad

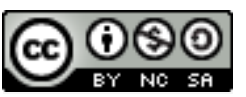

La Revista Estudios es editada por la Universidad de Costa Rica y se distribuye bajo una Licencia Creative Commons Atribución-NoComercial-Compartirlgual 3.0 Costa Rica. Para más información envíe un mensaje a revistaestudios.eeg@ucr.ac.cr. 
de decidir sobre la idoneidad del personal o los contenidos de las materias que se imparten en las escuelas y colegios del país (Cortés, 2013).

Sin embargo, es importante destacar que también se dan retrocesos significativos durante este período. Uno de ellos es el surgimiento y la creciente incidencia de partidos políticos de corte evangélico que reivindican una agenda política conservadora y fundamentalista enfocada en la lucha contra los derechos reproductivos (prohibición de la fertilización in vitro y de la anticoncepción de emergencia), los programas de educación sexual en las escuelas y los derechos sexuales. Esto posibilitó la formación de una alianza estratégica entre el conservadurismo católico y el evangélico (Fuentes, 2014).

En síntesis, este tercer y último período no puede caracterizarse como un periodo en el que exclusivamente se den avances o retrocesos en la secularización del Estado costarricense. Aunque se dan avances tales como la eliminación de la Missio Canónica, ciertamente también se dan retrocesos tales como el crecimiento de partidos políticos cristiano-evangélicos de corte fundamentalista y la formación de una alianza estratégica entre los grupos conservadores católicos y los evangélicos.

El siguiente cuadro (Cuadro 1) resume y caracteriza los períodos en la secularización del Estado costarricense:

\section{(a) $(10)$}

La Revista Estudios es editada por la Universidad de Costa Rica y se distribuye bajo una Licencia Creative Commons Atribución-NoComercial-CompartirIgual 3.0 Costa Rica. Para más información envíe un mensaje a revistaestudios.eeg@ucr.ac.cr. 


\section{Cuadro 1}

Periodización en la secularización del Estado costarricense

\begin{tabular}{|c|c|c|}
\hline Período & Avances & Retrocesos \\
\hline $\begin{array}{l}1^{\text {st }} \text { Período } \\
\\
\text { Desde } 1884 \text { hasta } \\
1940\end{array}$ & $\begin{array}{l}\text {-La reforma liberal: } \\
\text { Reforma educativa que } \\
\text { incluye la eliminación de } \\
\text { la enseñanza religiosa } \\
\text { obligatoria en las } \\
\text { escuelas públicas } \\
\text { Legalización } \\
\text { matrimonio civil y el } \\
\text { divorcio } \\
\text { Secularización de los } \\
\text { cementerios } \\
\text { Abolición del concordato } \\
\text { de } 1852 \\
\text { Secularización } \\
\text { registro de nacimientos y } \\
\text { muertes (creación del } \\
\text { Registro Civil) }\end{array}$ & \\
\hline $\begin{array}{l}2^{\text {nd }} \text { Periodo } \\
\text { Desde } 1940 \text { hasta } 2009\end{array}$ & & $\begin{array}{l}\text {-Restablecimiento de la } \\
\text { educación religiosa } \\
\text { obligatoria en las } \\
\text { escuelas } \\
\text {-"Recatolización" de la } \\
\text { educación }\end{array}$ \\
\hline
\end{tabular}

\section{(c) (i) (5)}

La Revista Estudios es editada por la Universidad de Costa Rica y se distribuye bajo una Licencia Creative Commons Atribución-NoComercial-Compartirlgual 3.0 Costa Rica. Para más información envíe un mensaje a revistaestudios.eeg@ucr.ac.cr. 


\begin{tabular}{|l|l|l|}
\hline & & $\begin{array}{l}\text {-Prohibición de la } \\
\text { fertilización in vitro }\end{array}$ \\
\hline $3^{\text {rd }}$ Periodo & $\begin{array}{l}\text {-Eliminación de la Missio } \\
\text { Canónica }\end{array}$ & $\begin{array}{l}\text {-Creciente incidencia de } \\
\text { partidos cristianos } \\
\text { fundamentalistas } \\
\text {-Alianza estratégica entre } \\
\text { el conservadurismo } \\
\text { católico y el evangélico }\end{array}$ \\
\hline
\end{tabular}

Fuente: Elaboración propia

\section{Conclusiones}

A mediados de la segunda década del siglo XXI Costa Rica era el único país en Latinoamérica que aún declaraba la confesionalidad estatal. No obstante, curiosamente también fue uno de los primeros Estados en la región que legalizó el divorcio y eliminó la educación religión de las escuelas públicas a finales del siglo XIX.

Basándose en el concepto de desecularización propuesto por el sociólogo Peter Berger, en este artículo se evidenció que la secularización del Estado costarricense nunca ha sido un proceso lineal ni progresivo. Por el contrario, éste mostró que ha sido un proceso tortuoso y complicado, con avances y retrocesos a veces incluso en un mismo período.

\section{(C) $(\Theta \odot$}

La Revista Estudios es editada por la Universidad de Costa Rica y se distribuye bajo una Licencia Creative Commons Atribución-NoComercial-CompartirIgual 3.0 Costa Rica. Para más información envíe un mensaje a revistaestudios.eeg@ucr.ac.cr. 
El caso de Costa Rica evidencia la enorme complejidad que tienen las relaciones entre la religión y el Estado, especialmente en Latinoamérica, y cuestiona las versiones más simplistas de la tesis de la secularización. Contrario a lo que pensaban Comte y muchos de los sociólogos y estudiosos de la religión de los siglos XIX y XX, la secularización no es un proceso lineal ni irreversible sino que tiene avances y retrocesos. Las reformas pueden ser revertidas y las leyes pueden ser cambiadas o incluso eliminadas, en especial si un amplio sector de la población no se siente identificada con ellas.

Las implicaciones políticas de esta última aseveración son el meollo del asunto tratado en este artículo. Así como dos mil quinientos años atrás Platón y Aristóteles ya advertían sobre la fragilidad y la incertidumbre de la democracia como régimen político, los retrocesos en la secularización, eso que Berger denomina desecularización, evidencian que tampoco existe ninguna certeza de que los avances alcanzados en materia de laicidad sean irreversibles.

\section{Referencias}

Arguedas, G. (2011). El (aún) tortuoso camino hacia la emancipación: fundamentalismos religiosos, los derechos humanos de grupos históricamente oprimidos y la lucha por un Estado laico en Costa Rica. Anuario del Centro de Investigación y Estudios Políticos, 1, 49-64.

\section{(cc) (P)}

La Revista Estudios es editada por la Universidad de Costa Rica y se distribuye bajo una Licencia Creative Commons Atribución-NoComercial-CompartirIgual 3.0 Costa Rica. Para más información envíe un mensaje a revistaestudios.eeg@ucr.ac.cr. 
Asamblea Legislativa de la República de Costa Rica (2009). Proyecto de Ley \# 17.511: reforma de los artículos 75 y 194 de la Constitución Política. Recuperado el 23 de agosto de 2017 de http://www.asamblea.go.cr/sil_access/ver_texto_base.aspx?Numero_Proyecto=17 511

Blanco, R. (1984). 1884 El Estado, la Iglesia y las reformas liberales. San José: Editorial Costa Rica.

Cortés, A, (2013, enero-junio). La educación religiosa en Costa Rica. Aproximaciones teóricas del campo religioso posteriores al voto de la Sala Constitucional. Revista Espiga, 25, 97-119.

Díaz-Arias, D. (2010, mayo-agosto). ¿Una Contra-reforma tropical? Estado, religión y lucha política en Costa Rica, 1940-1949. Revista Senderos, 96, 135-162.

Fuentes, L. (2014). El cristianismo en la matriz política del Estado. Laicidad y autonomía reproductiva en Costa Rica y Nicaragua. Anuario de Estudios Centroamericanos, 40, 11-36.

Fonseca, A. (2008). Pecado y delito en la mentalidad costarricense (un estudio filosófico). Tesis para optar al grado de Magister Philosophiae. San José: Universidad de Costa Rica.

\section{(@) $\odot \Theta(0)$}

La Revista Estudios es editada por la Universidad de Costa Rica y se distribuye bajo una Licencia Creative Commons Atribución-NoComercial-CompartirIgual 3.0 Costa Rica. Para más información envíe un mensaje a revistaestudios.eeg@ucr.ac.cr. 
Karpov, V. (2010). Desecularization: A Conceptual Framework. Journal of Church and State, 52 (2), 232-270. Recuperado el 6 de junio de 2016 de http://www.jstor.org/stable/23921866

Molina, I. (2007, agosto). Educación y sociedad en Costa Rica: de 1821 al presente (una historia no autorizada). Diálogos. Revista electrónica de la Escuela de Historia, 8 (2). Recuperado el 23 de agosto de 2017 de http://www.redalyc.org/pdf/439/43913793007.pdf

Picado, M. (1993). Los concordatos celebrados entre los países de Centro América y la Santa Sede. Revista de Historia, 28, 207-232.

Pollack, D. (2008). Religious Change in Europe: Theoretical Considerations and Empirical Findings. Social Compass, 55 (2), 168-186. Recuperado de http://journals.sagepub.com el 26 de agosto de 2015.

Sistema Costarricense de Información Jurídica (s.f.). Constitución Política de la República de Costa Rica. Recuperado el 24 de agosto de 2017 de http://www.pgrweb.go.cr/scij/busqueda/normativa/normas/nrm_texto_completo.asp x?param1 $=$ NRTC \&nValor $1=1 \&$ nValor2 $=871 \&$ strTipM $=$ TC

Vargas, C. (1991). El liberalismo, la Iglesia Católica y el Estado en Costa Rica. San José: Guayacán.

1 Una versión original de este trabajo fue presentada en la Conferencia Doctoral Enchantments, Disenchantments, Re-enchantments: Religion, State, and Society through

\section{(c) $($ ) $(2)(2)$}

La Revista Estudios es editada por la Universidad de Costa Rica y se distribuye bajo una Licencia Creative Commons Atribución-NoComercial-Compartirlgual 3.0 Costa Rica. Para más información envíe un mensaje a revistaestudios.eeg@ucr.ac.cr. 
History, organizada por el Center for Religious Studies de la Central European University en Budapest, Hungría, entre el 29 de junio y el $1^{\text {o }}$ de julio de 2017.

2 Otros casos como el de Irán o el de Afganistán ciertamente son aún más claros. Sin embargo existen pocos estudios al respecto en Latinoamérica.

\section{(c) (1) ()}

La Revista Estudios es editada por la Universidad de Costa Rica y se distribuye bajo una Licencia Creative Commons Atribución-NoComercial-Compartirlgual 3.0 Costa Rica. Para más información envíe un mensaje a revistaestudios.eeg@ucr.ac.cr. 